\title{
Primary essential cutis verticis gyrata - Case report
}

Jeane Jeong Hoon Yang ${ }^{1}$

Antonio José Tebcherani ${ }^{1}$

\author{
Daniela Tiemi Sano ${ }^{1}$ \\ Ana Paula Galli Sanchez ${ }^{1}$
}

Silvia Regina Martins ${ }^{1}$

Abstract: Cutis verticis gyrata is characterized by excessive formation of scalp skin. It may be primary (essential and nonessential) or secondary. In the primary essential form it presents only folding skin formation on the scalp, mimicking cerebral gyri, without associated comorbidities. We report a rare case of a 28 year-old male patient with primary essential cutis verticis gyrata.

Keywords: Hypertrophy; Rare diseases; Scalp dermatoses

\section{INTRODUCTION}

Cutis verticis gyrata (CVG) is a rare disease, congenital or acquired, characterized by the redundancy of skin on scalp, forming thick skin folds and grooves of similar aspect to cerebral cortex gyri. ${ }^{1,2,3}$ It may be classified into primary form (essential and nonessential) and secondary. Primary CVG is rare, characterized by the absence of neurological and ophthalmological changes and by exclusion of secondary causes of the disease. ${ }^{1}$ We report a typical and exuberant case of primary essential CVG in a young adult.

\section{CASE REPORT}

Male patient, 28 year old, of mixed race, presented for two years scalp skin redundancy, with deep cerebriform folds and wrinkles, located in parietaloccipital regions (Figures 1 and 2). He denies comorbidities, similar family history, consanguinity and usage of anabolic steroid drugs, as well as skin and scalp inflammatory disease history. He did not present neurological or ophthalmological changes. The anatomopathological exam revealed epidermis and dermis within histological standards of normality (Figures 3 and 4), the clinical picture being compatible with CVG. For the exclusion of secondary causes by acromegaly and pachydermoperiostosis the following

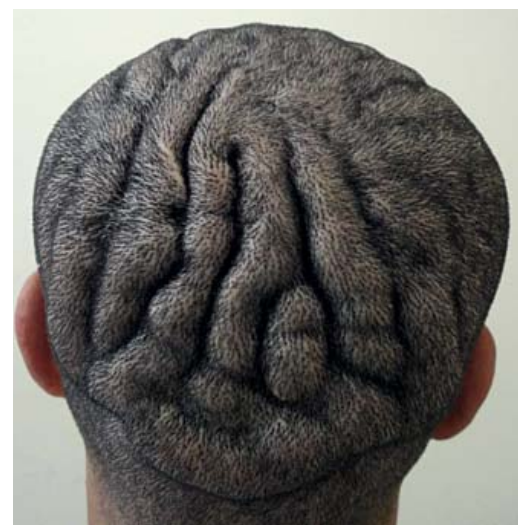

FiguRE 1: Cutis verticis gyrata. Cutaneous hypertrophy with cerebriform aspect of scalp, anteroposterior disposition in parietal regions and horizontal in occipital region

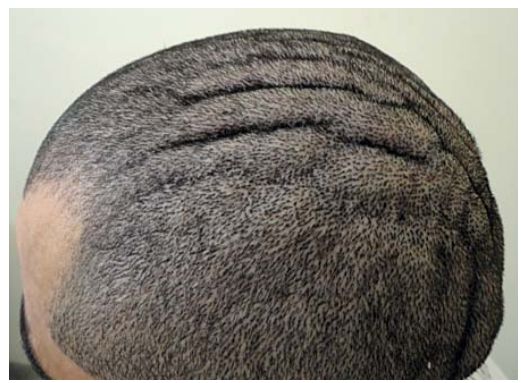

FIGURE 2:

Cutis verticis gyrata. Scalp hypertrophy with anteroposterior folds in parietal region

\footnotetext{
Received on 09.07.2013.

Approved by the Advisory Board and accepted for publication on 08.08.2013.

* Work performed at Complexo Hospitalar Padre Bento de Guarulhos (CHPBG) - Guarulhos (SP), Brazil.

Conflict of Interests: none

Complexo Hospitalar Padre Bento de Guarulhos (CHPBG) - Guarulhos (SP), Brazil.
} 


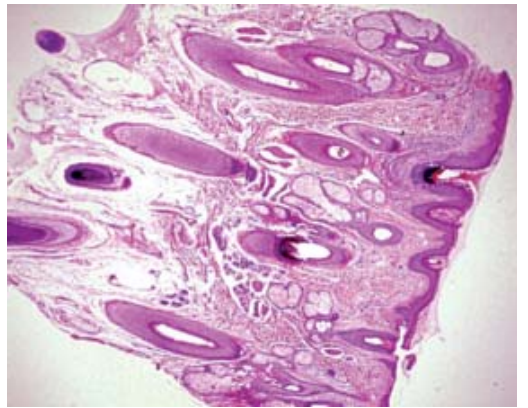

FIGURE 3:

HE. 40x.

Epidermis and dermis within normality standards for the biopsied region

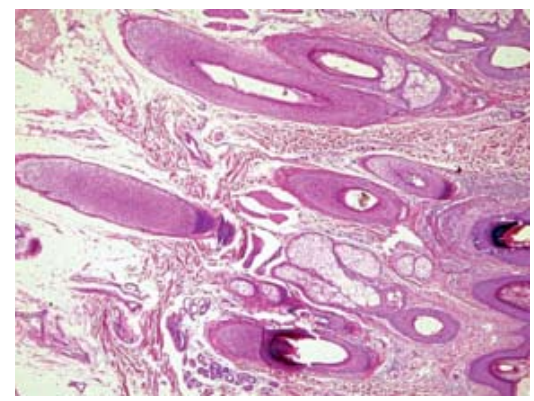

FiguRE 4: HE.100x. Dermis and cutaneous annexes within normality standards. Absence of dermal deposits

tests were performed: skull X-ray, computed tomography of skull and sella turcica, nuclear magnetic resonance of the sella turcica and serum growth hormone dosage, which showed no alterations. Conditions associated with CVG were discarded: myxedema, leukemia, acanthosis nigricans, diabetes mellitus, syphilis by TSH serum dosage, free T4, complete blood count, fasting blood glucose, total cholesterol and fractions, and Venereal Disease Research Laboratory test - VDRL. All results were within normal limits.

\section{DISCUSSION}

CVG, also known as paquidermia verticis gyrata, cutis verticis plicata and "bulldog" scalp syndrome was originally described in 1837 by Jean-Louis-Marc Alibert, the term cutis verticis gyrata being proposed by Unna in 1907. ${ }^{4}$ In 1953 Polan e Butterworth classified CVG into two forms: primary and secondary.

The primary form can be divided in essential and non-essential.

The primary essential form, presented by our patient, predominates in men (association five times more frequent compared to women). ${ }^{5}$ Usually, the clinical picture starts during or after puberty, occurring especially after 30 years of age. There is no association with other comorbidities like, for instance, neurological and ophthalmological diseases, and only formation of skin folds on the scalp is found. ${ }^{1}$
The nonessential form presents association with several neurological manifestations (microcephaly and seizures, mental retardation, cerebral palsy, epilepsy) or ophthalmological changes (cataract, strabismus, blindness, retinitis pigmentosa). ${ }^{1}$ The secondary form may arise from use of drugs like anabolic steroids. ${ }^{6}$ It may also be associated with inflammatory or neoplastic processes that cause changes in the scalp structure such as: osteoarticular diseases (pachydermoperiostosis, acromegaly), pituitary tumors, intracerebral aneurysm, tuberous sclerosis, amyloidosis, myxedema, dermatofibroma, acanthosis nigricans, acne conglobata, cerebriform intradermal nevus, cutaneous focal mucinosis, scalp psoriasis, syphilis, diabetes mellitus type 2 . It may also occur in association with various syndromes (Noonan syndrome, Beare-Stevenson syndrome, Ehlers-Danlos Syndrome, "Michelin tire baby" syndrome, Turner syndrome and fragile $X$ syndrome). ${ }^{2,3}$

In the case of our patient, the cutaneous changes had appeared spontaneously two years before, without history of any of the comorbidities above mentioned.

Primary CVG presents as symmetric scalp folds which usually extend anteroposteriorly from vertex to the occiput and can present transversally in the occipital region, as observed in our patient. ${ }^{1}$ The anatomopathological exam may reveal an essentially normal skin structure or skin with thickened connective tissue with hypertrophy or hyperplasia of adnexal structures. ${ }^{7}$

Among the differential diagnoses we can mention pachydermoperiostosis, acromegaly, cutis laxa, cylindroma, cerebriform intradermal nevus and inflammatory diseases of the scalp. ${ }^{8}$

The treatment for primary essential CVG may be symptomatic or surgical. Orientation regarding local hygiene care is necessary to avoid secretion accumulation with unpleasant odor. Surgical treatment may be performed with the goal of improving the clinical aspect, for quality of life might be compromised due to unesthetical aspect. ${ }^{9}$ As surgical options we can mention total resection of the lesion and grafting, placement of tissue expander in healthy skin and later grafting and partial resection of abundant portion of lesion..$^{10}$ Our patient was advised to observe local hygiene and awaits surgical treatment.

In conclusion, primary essential CVG is an extremely rare condition. The diagnose of primary essential CVG can only be defined after excluding neurological and ophthalmological alterations, as well as diseases possibly associated with the onset of CVG. The dermatologist facing this picture must perform careful anamnesis and complementary exams to corroborate the diagnosis. $\square$ 


\section{REFERENCES}

1. Diven DG, Tanus T, Raimer SS. Cutis Verticis Gyrata. Int J Dermatol. 1991;30:710-2.

2. Schöttler L, Denisjuk N, Körber A, Grabbe S, Dissemond J. Asymptomatic cerebriform folds of the scalp. Diagnosis: primary Cutis verticis gyrata (CVG). Hautarzt. 2007; 58:1058-61.

3. Larsen F, Birchall N. Cutis verticis gyrata: Three cases with different aetiologies that demonstrate the classification system. Australas J Dermatol. 2007;48:91-4.

4. Polan S, Butterworth T. Cutis verticis gyrata. A review with report of seven new cases. Am J Ment Defic. 1953;57:613-31.

5. Lasser AE. Cerebriform intradermal nevus. Pediatr Dermatol. 1983;1:42-4.

6. Ross JB, Tompkins MG. Cutis verticis gyrata as a marker of internal malignancy. Arch Dermatol. 1989;125:434-5.

7. Snyder MC, Johnson PJ, Hollins RR. Congenital primary cutis gyrata. Plast Reconstr Surg. 2002;110:818-21.

8. Cribier B, Lipsker D, Mutter D, Grosshans E. Cutis verticis gyrata: reduction surgical treatment. Ann Dermatol Venereol. 1993;120:542-5.

9. Dumas P, Medard de Chardon V, Balaguer T, Cardot-Leccia N, Lacour JP, Lebreton E. Primary essential cutis verticis gyrata: Case report and literature review. Ann Chir Plast Esthet. 2010;55:243-8.

10. El-Husseiny M, Yarrow J, Moiemen N. Primary cutis gyrata: review of literature and a successful new surgical approach. Eur J Plast Surg. 2010;33:153-7.

\author{
MAILING ADDRESS: \\ Jeane Jeong Hoon Yang \\ AV. Emílio Ribas, 1819 - Gopoúva \\ 07051-000 - Guarulhos - SP \\ Brazil \\ E-mail: jeanejhy@uol.com.br
}

How to cite this article: Yang JJH, Sano DT, Martins SR, Tebcherani AJ, Sanchez APG. Primary essencial cutis verticis gyrata - Case report. An Bras Dermatol. 2014;89(2):326-8. 